\title{
EL PARADIGMA ANTROPOCÉNTRICO: SUS RAÍCES JUDEO-CRISTIANO Y CIENTÍFICO-TÉCNICO CARTESIANO COMO CAUSAS CULTURALES DE LA CRISIS ECOLÓGICA
}

\author{
Héctor MORÁN SEMINARIO \\ Universidad Ricardo Palma \\ hmoran@urp.edu.pe
}

\begin{abstract}
RESUMEN
Desde una perspectiva de la ecofilosofía se reflexiona sobre la problemática de la crisis planetaria del medio ambiente. El documento está divido en dos partes. La primera, discurre sobre el tema de la naturaleza cuyo concepto es profundamente cultural, y ha evolucionado históricamente, pues el hombre ha ido construyendo sus imágenes de la naturaleza en íntima relación con la misma percepción que iba construyendo sobre sí mismo. La segunda parte, aborda la ideología del antropocentrismo, sobre todo en la modernidad y su enraizamiento en la ideología religiosa judeo-cristiana, y la nueva ciencia y técnica de origen cartesiano que delimitará radicalmente el binomio hombre-naturaleza mostrándose como génesis de por qué en nuestro tiempo predomina una visión de la naturaleza influenciada por la visión cientifista, entendida como aquello que es objeto de observación, medición, experimentación. El propósito central del trabajo es, fundamentar que las causas más profundas de la actual crisis medioambiental que afrontamos, son de naturaleza cultural-civilizacional de Occidente.
\end{abstract}

\section{PALABRAS CLAVE}

Antropocentrismo. Ecofilosofía. Crisis medioambiental. Cientificismo. Cultural-civilizacional.

\section{THE ANTHROPOCENTRIC PARADIGM: ITS JUDEO-CHRISTIAN AND SCIENTIFIC-TECHNICAL CARTESIAN ROOTS AS CULTURAL CAUSES OF THE ECOLOGICAL CRISIS}

\begin{abstract}
From an eco-philosophy perspective, we reflect on the problem of the crisis of the planetary environment. The document is divided into two parts. The first one deals with the subject of nature and bases the concept of nature as deeply cultural, and has evolved historically since man has been constructing his images of nature in close relation with the same perception he was building on himself, or On the "man". The second part deals with the ideology of anthropocentrism, especially in modernity and its rootedness in Judeo-Christian religious ideology, and the new science and technique of Cartesian origin that will radically delimit the binomial man-nature being shown as the genesis of why in our Time predominates a vision of nature predominantly influenced by the scientific vision, understood as that which is object of observation, measurement, experimentation. The central purpose of the paper is to justify the fact that the deepest causes of the current environmental crisis we face are of the cultural-civilizational nature of the West.
\end{abstract}

\section{KEYWORDS}

Anthropocentrism. Ecofilosofía. Environmental crisis. Cientificismo. Cultural-civilizational. 


\section{LA NATURALEZA: concepciones}

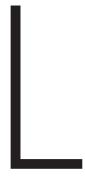

a respuesta a la pregunta sobre qué es la naturaleza no es tan simple como aparenta, aunque se podría responder que se trata de "todo aquello que no es artificial".

Las diferentes concepciones de naturaleza formuladas por el hombre, dentro de una perspectiva de las ciencias sociales, son resultado de condiciones históricas y políticas, como seguidamente lo fundamentaremos. Así, por ejemplo, el concepto de naturaleza como lo entendieron los griegos hacía referencia a la phisys, es decir lo no creado ni sujeto a mandato alguno - ni humano ni divino. Siendo así, ella sólo se rige por sus propios ritmos y leyes intrínsecos, sin objetivos predeterminados, aunque, si es que tuviera finalidad alguna, sería su "propia finalidad", en el sentido de su evolución o degeneración. Podríase afirmar que la naturaleza es indiferente a lo que ocurra en el cosmos, pues, sólo le guía - por decir de algún modo- su propia teleología. De aquí se sigue, que el destino de los seres que la habitan y que, más bien, sus existencias quedan condicionadas por ella, pero no a la inversa. O sea, ella seguirá, necesariamente, su desarrollo así dejen de existir los seres vivientes, incluida la especie humana.

Sin embargo una definición más elaborada sobre lo que sea la naturaleza va a depender de una serie de factores intrínsecos al momento histórico-cultural de quien responde, como también de sus intereses de clase. De acuerdo con Goncalves (1990:23), la historia es el hilo conductor de cómo los hombres perciben la naturaleza en diferentes momentos. Pues determinada forma de percibir la naturaleza traduce la forma de relacionarse con la misma. En la antigüedad, sólo para ilustrar en una época, el hombre se encontraba más bien próximo y dependiente de su medio natural, a causa de su escasa tecnología para actuar sobre ella. Para él, la naturaleza estaba estrechamente ligada a su cotidianidad, a su forma de vivir, casi indisociable de su yo. Él retiraba de la naturaleza lo justo para su supervivencia así como para realizar ofrendas para el culto a las divinidades. Aún hoy todavía existen algunos grupos indígenas que tienen este tipo de relaciones con la naturaleza, como es el caso de los pueblos de las serranías o los grupos étnicos de la Amazonía peruana, la comunión con la naturaleza es parte de su cosmovisión.

\section{Fragmentación de la sociedad y de la naturaleza}

Históricamente con el surgimiento de la propiedad privada el hombre se torna sedentario y comienza a producir excedentes, tiene inicio la división de la sociedad en clases sociales; entonces, la relación primigenia en forma de comunión entre hombre y naturaleza es rota. Y la naturaleza comienza a ser apropiada, aunque la apropiación de sus recursos no lo será de forma igualitaria ni justa por el conjunto de los hombres, sino más bien de acuerdo con los intereses de quien detenta el poder, lo que a su vez se traducirá, a nivel superestructural, también, en una determinada concepción sobre la naturaleza, como pasaremos a revisar.

\section{- La antigüedad y la mentalidad tradicional.}

Etimológicamente, para los griegos clásicos de los siglos V y IV A.C Kosmos significaba Orden y Uranos significaba Cielo. En razón de ello es que éstos consideraban que el Mundo 
era un Todo ordenado. Concepción que se trasladaba a la Polis griega, entendida como una integración única: Kosmopolis. Aquí radicaría la raíz de la relación armónica entre la naturaleza y el Hombre. Teniendo en consideración que hasta los dioses eran de textura y poderes naturales más que celestes. Muchos filósofos griegos contribuyeron a la discusión acerca de la naturaleza, como Sócrates, Platón y Aristóteles, para citar algunos.

Aristóteles (384-322. A.C) es uno de los formuladores del modelo de universo donde la tierra se encontraría fija y localizada en el centro del universo. Ese modelo resistió al período de dominación del imperio romano y fue apropiado, en la edad media, por la iglesia católica en cuanto doctrina. No fue una apropiación pura, sino con adaptaciones compatibles con los intereses de la Iglesia en la época.

Posteriormente en la mentalidad helenística y escolástica la materia, -la naturaleza-, ocuparía un lugar inferior y la forma un lugar superior. Esto quiere decir, que la forma existe independientemente de la materia o la inteligencia. Así, para Aristóteles Dios es Inmutable y como motor inmaterial contiene los principios organizadores que dan forma a la materia. En cambio para Platón Dios es la inteligencia superior demiurgica, la mente absoluta; en cambio para Plotino la materia es principio de todo el mal.

\section{- $\quad$ Edad Media}

Aproximadamente a partir del siglo XIII comienza un proceso de significativos cambios en el interior del modo de producción feudal europeo, que a pesar de ser muy gradativos, se muestran irreversibles. "En la etapa medieval, ya se pensaría que los seres humanos se encuentran vinculados de manera armónica con el sistema de las cosas naturales y que tiene su propio sitio definido dentro del orden global de la naturaleza. Se resalta mucho más lo espiritual antes que lo material, por eso lo físico, lo corpóreo eran subvalorados y ubicados en los grados inferiores de la escala axiológica". (Rivera, 1994: 27).

\section{- La mentalidad moderna}

El centro dinamizador de novedosas modificaciones es el surgimiento de una clase revolucionaria formada por la burguesía, que vendría a consolidar el modo de producción capitalista. Para una efectiva materialización del poder en manos de la burguesía eran necesarios cambios estructurales revolucionarios en todo el sistema vigente, no sólo dentro de la perspectiva económica, sino en las relaciones sociales mismas y en la forma de concebir el mundo por el hombre. Entonces surgen la Reforma Protestante en Alemania y el Renacimiento en Italia, teniendo su cúspide en la revolución Industrial en Inglaterra y la Revolución Francesa en el siglo XVIII. Eso consolidó el capitalismo en cuanto nuevo modo de producción que se diseminó por el mundo.

Estos cambios ocurridos de forma efervescente en Europa no podían dejar de influir en pensadores que buscaban concebir el mundo a partir de otras perspectivas, además de las ofrecidas por las sagradas escrituras. En este sentido, una nueva concepción que sacudirá los conceptos de universo de la Iglesia será la de Nicolás Copérnico (1473-1543), y su teoría heliocéntrica. No se trataba sólo de nuevos presupuestos ligados exclusivamente a la astronomía, sino que representaban una verdadera revolución en la forma de pensar sobre el mundo. En el desarrollo de los acontecimientos tenemos a Johannes Kepler 
(1571-1630), responsable de la elaboración de la teoría de que las órbitas de los planetas eran elípticas, cuestionando así la teoría de las órbitas en circunferencia pregonada por la tradición aristotélica y aún por la ptolemaica.

Galileo Galilei, valiéndose de la experimentación científica y del lenguaje matemático, dará contornos más nítidos a las teorías formuladas por Copérnico y Kepler, materializándose en una nueva forma de ver el mundo. Según Moreira (1991: 81), "Sellando esta nueva concepción que separa y aísla como naturaleza un mundo que está escrito en lenguaje matemático, Galileo dice que de ella no hacen parte Dios y el hombre". Constatamos que esta concepción de naturaleza queda sujeta a la ciencia, que debe estudiarla. Sin embargo, es una naturaleza sin el hombre, el cual, junto con Dios, debe ser estudiado por la metafísica.

Francis Bacon, formula, quizás por primera vez, la idea de que el "conocimiento es poder", percibiendo el valor metodológico instrumental de la inducción que partiendo de la observación y comprensión del funcionamiento de la naturaleza como el único procedimiento para poder "dominarla" y controlarla de acuerdo con los intereses del hombre.

Con Rene Descartes, la racionalidad mecanicista va a ser más bien sistematizada. La naturaleza va a ser concebida de acuerdo con las características de la filosofía cartesiana, quedando marcados los grandes aspectos que caracterizarán a la modernidad:

a. El carácter utilitarista que el conocimiento adquiere: "conocimientos que sean más útiles a la vida (...) en vez de esa filosofía especulativa que se enseña en las escuelas"- coloca a la naturaleza como un recurso, es un medio para conseguir un fin.

b. El Antropocentrismo, esto es, el hombre pasa a ser el centro del universo, el sujeto, en oposición al objeto: la naturaleza.

De lo que resulta entonces, que el método cartesiano orienta hacia la división del objeto que se busca conocer separándolo en tantas partes como sean posibles, y estudiar minuciosamente cada una de ellas guiándose por la razón, con el objetivo de comprobar o refutar las hipótesis formuladas, posibilitando el "dominio" de la naturaleza por el "hombre".

Por otro lado, en este tiempo y en esta atmósfera cultural el "mundo máquina" de Newton resultaba conveniente y revolucionario, pues se trata de una época en que la industrialización era algo nuevo representando el futuro y la modernidad, que posibilitó un acercamiento entre ciencia, técnica y desarrollo económico.

Según Becker y Gomes (1993:150-151), la concepción de naturaleza en aquel período pasaba por las siguientes observaciones: Primero, la concepción de naturaleza se transforma en un sistema de leyes matemáticas establecidas por un Dios racional (...). La analogía con la máquina es característica fundamental de esta época que vio nacer la revolución industrial, o sea, tal cual una máquina, la naturaleza está formada de unidades diferentes, unidas por mecanismos lógicos y necesarios produciendo, como resultado, un movimiento armonioso y concertado. Segundo, era un casamiento perfecto entre la ciencia y la nueva era industrial, que concebirá a la naturaleza como proveedora de recursos, y ella misma como el más importante recurso a ser absorbido por el capitalismo industrial, después será absorbido el propio hombre.

Digamos que los pensadores modernos construyeron una nueva concepción del 
mundo y de la naturaleza que difería sustancialmente de la visión tradicional. Esta nueva concepción moderna del siglo XVII era dualista. Quiere decir, que opusieron la mente a la materia, el pensamiento a la extensión, los valores a los hechos, y la humanidad a la materia. (Rivera. 1994:28).

En síntesis, la naturaleza a partir de allí sería convertida en objeto de control, explotación y dominación técnico - científica. Lo que permitirá culminar el proceso de alienación que se manifestará en el gobernarla sobre la base de su objetividad autónoma.

\section{La imagen de naturaleza en la ciencia}

Para la ciencia contemporánea, la naturaleza es la esfera de los objetos perceptibles y observables: materia inerte por la que no se tiene ningún sentimiento de respeto por no haber deberes hacia ella de parte del hombre. Más bien está allí para ser expoliada y usufructuada para satisfacción de las necesidades humanas. Se reconoce hacia ella la idea de un dualismo: hombre- naturaleza, en el cual siempre ha de predominar uno de los dos, visión presente en cualquier sistema de valuaciones del pensamiento.

Este dualismo, para W. Leiss (1972:128), es todavía más radical: "En correspondencia con las dos esferas de la actividad humana, en la vida moderna existen dos naturalezas: la naturaleza intuida (...) y la naturaleza científica (...), la naturaleza de la que se tiene experiencia en la vida cotidiana, y la naturaleza matematizada, universal- abstracta, de las ciencias físicas. Por lo general, la primera no constituye un interés "temático" para la ciencia, sino que subsiste más bien como el trasfondo familiar que unifica, en cierta medida, la experiencia humana a escala universal, a pesar de todas las diferencias culturales e históricas".

Esta dualidad del término naturaleza, en nuestros tiempos, ha sido relacionada con la naciente cultura "medio- ambientalista", la que pretende postularse como la alternativa a la perspectiva del antropocentrismo dominante, que aún resiste toda interpretación que pretenda destruir su predominancia cultural, no permitiendo encontrar razones justificadoras en favor de la protección y la defensa de la naturaleza.

Resumiendo, y en la línea de la premisa inicial del capítulo, el concepto de naturaleza es profundamente cultural, y ha evolucionado históricamente. Como ya se ha explicado, el hombre ha ido construyendo sus imágenes de la naturaleza en íntima relación con la misma percepción que iba construyendo sobre sí, o sea, sobre el "hombre". Pero será en la modernidad, la ideología religiosa judeo- cristiana, y la nueva ciencia la que delimitó radicalmente el binomio hombre - naturaleza. Es por ello que en nuestro tiempo predomina una visión de naturaleza predominantemente influenciada por la visión cientifista, entendida como aquello que es objeto de observación, medición, experimentación.

Será el cientificismo, como ideología dominante en la filosofía de la ciencia, que profundizará aún más esta separación; se constituirá en el sustento teórico para construir el modelo de desarrollo dominante, basado en la "cosificación" de la naturaleza y por consiguiente, en una "justificación moral" para la destrucción del ecosistema planetario.

En conclusión, la concepción de naturaleza está ligada a la propia concepción del hombre. 


\section{ANTROPOCENTRISMOY MEDIOAMBIENTE}

\section{Visión filosófica de las relaciones del hombre con la Naturaleza}

Para W. O'Briant (1974:79), en la historia de la filosofía occidental es posible identificar dos maneras opuestas de entender la relación del hombre con la naturaleza. Estas dos concepciones se las podría denominar en general como:

a) La del hombre separado de la naturaleza; y b) la del hombre como parte de la naturaleza.

La primera, según O'Briant, estaría fundamentada en el presupuesto de que el hombre sería "una criatura única", dotada de unas facultades que la distinguen radicalmente de cualquier otro ser vivo en la tierra; tal sería, por ejemplo, la de poseer "alma", lo que vendría a significar que la tal sui- géneris particularidad radicaría en que él es de hechura sobrenatural de un Dios creador de quien, sin duda, él está hecho a su imagen. Y lo que es más, harían de él un ser que no es totalmente "natural", sino que más bien, en algunos respectos, pertenecería a un mundo "no natural", diferente del resto de los seres terrenales. Entonces ya no es difícil comprender la raíz del sentimiento de superioridad de que se autoinviste $y$, por tanto, justifica el derecho que se arroga a la toma de posesión de la naturaleza.

La segunda posición, por el contrario, se sustenta en la presunción de que el hombre es "un animal entre muchos otros animales", de los que difiere, no por su género, sino sólo en el grado (O'Briant, 1974:79). Esto significa que la diferencia de grado radica en la posesión de una capacidad mayor por su mejor uso que hace de la razón (aunque sus actuaciones no siempre están justificadas racionalmente). De aquí se seguiría entonces, que en esta posición el hombre no puede reivindicar el derecho a ejercer un dominio sobre las otras criaturas, incluyendo la naturaleza.

Para nuestro autor, en esta segunda visión subyacería una visión "monista" del hombre, pues excluye la distinción entre "cuerpo y alma"; y, desde luego, cualquier tipo de fe en la existencia de un mundo sobrenatural al que habría que referir la dimensión "superior" (o alma). Una visión contraria encontraremos más adelante en Descartes.

\section{Animismo o Antropocentrismo: dos alternativas para repensar la Naturaleza}

En el núcleo de la racionalidad de dominio sobre la naturaleza de Occidente está instalada una concepción antropocéntrica muy arraigada. Lo que lleva a La Torre (1993:83) a sostener que, o el animismo o el antropocentrismo son las alternativas históricas más plausibles en una visión sobre la naturaleza.

\section{La concepción animista}

Sostiene La Torre, que a diferencia de los hombres modernos que tienen una distinción muy nítida entre hombre y naturaleza, donde el entorno se considera como algo que no es social, el hombre primitivo entiende y hace una lectura de la naturaleza basándose en normas morales; esa es la actitud animista. Esta mentalidad implica que el hombre primitivo no buscará en la naturaleza explicaciones (o sea, razones para entender sus relaciones en 
el mundo), sino más bien vive en el mundo de una manera emotiva y fantástica, y de ahí se procurará normas de comportamiento, vale decir normas morales (p: 41).

Ahora bien, si es verdad que en el hombre primitivo prevalece la emotividad sin embargo, este hombre, al contrario del hombre moderno occidental, no se considera señor de la naturaleza, superior a los animales, a las plantas, a las cosas inanimadas, (como lo permite considerar el mito de la creación) sino que más bien se considera como su igual, e incluso, en ocasiones, como inferior a ella y trata a los otros seres y las cosas con respeto y temor (Ibíd. :41). De allí se sigue entonces, que el hombre primitivo concibe a la naturaleza como una totalidad animada por espíritus. Espíritus que son interpretados con la idea y la percepción que el hombre tiene de sí mismo. Aquí, pues, radicaría la conciencia de este hombre que considera que no tiene una diferencia sustancial entre él y el animal. Como en este tipo de organización social el individuo esta subsumido en el entorno y avasallado más bien por él, desarrollará una interpretación animista de la naturaleza y de sus fuerzas. Lo que va a implicar que para él la naturaleza sea tenida como un algo animado que reclama un respeto de tipo casi religioso.

Digamos que en esta etapa el hombre y la naturaleza no se encuentran enfrentados como dos entes antagónicos, sino que ni siquiera existe diferenciación entre ambos respecto a valor o dignidad y derecho a su existencia, por el contrario, están íntimamente unidos en una totalidad orgánica u holística.

\section{La concepción antropocéntrica}

Según Spinoza (Taguieff, 1994: 265-267), el antropocentrismo es un prejuicio fundamental. Los hombres en su ignorancia son llevados a creer que todas las cosas han sido hechas para ellos y que por tanto todo cuanto ocurre se relaciona a ellos mismos, a sus expectativas, intereses, pasiones. Ellos consideran a la naturaleza como el campo en el cual ejercer su libertad, vale decir dar escape a sus impulsos y deseos. Todas las cosas existentes en la naturaleza son vistas desde los hombres como medios para lograr su propio beneficio; ellos piensan que Dios mismo habría creado la naturaleza para ponerla al servicio de los hombres a fin de que ellos pudiesen dar escape a su "ciega codicia e insaciable avidez". De este modo "el prejuicio se ha transformado en superstición radicándose profundamente en las mentes".

En la filosofía panteísta de Spinoza la naturaleza es Dios ("Deus sive natura") y la búsqueda filosófica se dirige a las leyes universales de la naturaleza que no son otras que eternos decretos de Dios. En esta prospectiva la naturaleza es inviolable y recomprende en sí cada realidad. La crítica de Spinoza al antropocentrismo es contemporáneamente un intento de unir dos diversos ideales cognoscitivos en lucha entre ellos y que son destinados a quedar separados (a menos que sea en verdad posible una "nueva alianza").

A su vez, para la antropología el antropocentrismo es la actitud según la cual el hombre es considerado como la especie más importante del planeta (por lo tanto, lo que es bueno o justo para él, lo es también para cualquier otra forma de vida), el hombre aparece como medida de referencia en toda valoración del mundo, en una clara "Homomensura" a lo Protágoras. Precisamente aquí encontramos los orígenes de la mentalidad de dominio en la cultura y el hombre occidentales. Y es que esa jerarquía y "superioridad" de que se 
autoinviste el hombre en esta concepción, no son sino decir "superioridad" ante todos los demás seres de la naturaleza.

\section{Raíces culturales de la mentalidad antropocéntrica moderna}

Intentando encontrar razones suficientes que sustenten la nueva concepción de naturaleza construida en el desarrollo de la "nueva ciencia", en la cual el hombre ocupará el lugar central del universo (léase antropocéntrico) y desde la cual se verterán las explicaciones de todo lo que acontece en el universo, Cantoni cuestiona la forma "autoritaria" en que se construye esta nueva imagen del mundo como tipo definitivo de saber.

Por su parte Abugattás (1992), en su artículo "Marco conceptual de la ciencia y la tecnología" nos muestra que la noción de "individuo" es de crucial importancia para la formación de la concepción antropológica de la modernidad que se ha de implantar como el paradigma cultural vigente hasta nuestros días y que, en nuestra argumentación, consideramos como "causa sine qua non" de la crisis ecológica mundial.

Alrededor de esa idea (de individuo) gira toda la filosofía, sostiene Abugattás, todo el pensamiento moderno. Ni las teorías morales, ni políticas, ni las especulaciones gnoseológicas y ontológicas son entendibles si no se las ve desde la perspectiva del individuo autónomo y racional, que es el protagonista central de la modernidad. Eso mismo vale, en consecuencia, en lo que atañe a la ciencia y a la tecnología.

Considerando que éstas se moldearán, sobre todo la tecnología, a satisfacer sus necesidades. "En verdad creo que se puede mantener que tanto una como la otra deben sus características más saltantes al hecho de tener que servir a los intereses del individuo, para lo cual deben adaptarse a sus deficiencias y supuestas capacidades" (p: 13).

\section{La matriz cristiana}

Siempre con Abugattás, este individuo moderno o "sujeto individual" será el fruto de un largo proceso de "maduración cultural" enraizándose en el judeo-cristianismo y sus ideas de "libre albedrío y salvación individual" consolidándose en el "capitalismo mercantilista": con quien, en adelante, su objetivo y valor supremo será: la "acumulación" de riqueza, a diferencia de los antiguos y medievales que se guiaban por las virtudes de la moderación y la templanza.

En este camino emergente el hombre moderno está impulsado por el afán de traspasar límites y abarcarlo todo; en esta ambición la ciencia y la tecnología serán sus instrumentos. Pero en este camino hay un inconveniente que es, según Abugattás, DIOS. Pero resulta que "La ciencia moderna supone, más aún, demanda la muerte del viejo Dios, de ese Dios cuya benevolente intervención es necesaria para paliar o compensar las deficiencias de la razón. La ciencia moderna significa la emancipación de la razón natural" (p: 14).

\section{Antropocentrismo en la ciencia}

Otra de las raíces que sustenta el antropocentrismo en el pensamiento cultural de Occidente es una cierta visión de la ciencia que es engendrada por Descartes. En la visión dualista, mecánica y fragmentaria del mundo formulada por Descartes: Hombre- Naturaleza, 
la mente es considerada como lo único que tiene valor intrínseco y, por tanto las cosas materiales quedan reducidas como cosas sin importancia moral, lo que ha conducido sin dudas a un conjunto de valores antropocéntricos inaceptables.

Ahora, este hombre cartesiano es el que posee el método científico y con él puede, entonces, penetrar en los misterios de la naturaleza y así tornarse "todopoderoso"- "Señor y poseedor de la naturaleza". Con lo que ahora el poder desciende de los cielos a la tierra.

Reforzando nuestra afirmación Gould (1994) nos dice, que a partir de Descartes y su hombre armado del método científico como instrumento racional de poder para la dominación, el saber, haciéndose potencia, convence a los hombres del poder de realizar un dominio ilimitado sobre la naturaleza, la cual pierde su estatuto ontológico, la verdad no reside más en el "orden estable e inmutable de la naturaleza" sino en la actividad de transformación del hombre, es la técnica que realiza la verdad: "por medio del dispositivo técnico, la razón geométrica y algebraica no se satisface más de descubrir la mathesis universal en la naturaleza, puede proyectarla en concreto, constituirla como mundo delante de sí, espejo de la misma certeza" (p: 33).

De lo que resulta pues, que la cultura científica de Occidente, en su orgullo antropocéntrico, por desgracia, no ha sabido apreciar hasta ahora la conciencia de la ignorancia. Efectivamente, si nos remontamos a Descartes y Galileo, siempre se ha resaltado exclusivamente el lado positivo y exitoso de la ciencia, la promesa de un método que permitiría descubrir todas las verdades posibles. Este método debía generar la futura conquista de la naturaleza, siguiendo el ejemplo de las conquistas coloniales; de esta manera debía engendrar el triunfo de la civilización racional europea. Hasta hace poco hubiera parecido paradójico, incluso chocante, considerar "desafortunado" este modo de ver la ciencia (Taguieff, 1994: 265-267).

Por tanto, la visión antropocéntrica viene enormemente reforzada de la potencia de la técnica moderna, plenamente desplegada en el Novecientos. Por lo que el antropocentrismo no nacería de la fuerza sino de la debilidad del hombre frente a la naturaleza, de su falta de dotación natural que lo ponga en condiciones de afrontar los peligros del ambiente. Pues ya en los años veinte del siglo XX, Helmut Plessner (Gould, 1994: 67) había comenzado a relacionar la debilidad del sistema instintivo humano, con los consiguientes problemas de relaciones con el ambiente, a la construcción de "prótesis", esto es prolongamientos simbólicos de los órganos, capaces de realizar un creciente dominio de la realidad, que no es sino la tecnología.

Digamos que el antropocentrismo irrumpe y cobra significado cuando se pasa de una posición de subordinación a una de dominio. Tal cambio, es el fruto de un largo proceso que seguramente se hace efectivo solo con la difusión de las tecnologías industriales. Por esto aún en los inicios del Ochocientos, Hegel todavía puede pintar al campesino como un hombre que está en relación inmediata con la naturaleza: "ellos aran, siembran, pero es Dios que da la buena cosecha, las estaciones y la seguridad que crezca de sí aquello que ellos han colocado en el terreno. La actividad es lo sucedáneo" (En: Filosofía del espíritu).

La disponibilidad de una tecnología capaz de dominar la naturaleza, de destrozar la condición de subordinación en la cual se encuentran desde siempre los hombres, parece 
conceder a ellos la posibilidad de realizar el proyecto antropocéntrico; de una condición de necesidad se pasa a la de libertad, pero esta libertad se puede mantener solo si los hombres demuestran estar en condiciones de usar la técnica para realizar la potencialidad humana sin destruirse a sí mismos y destruir su ambiente de vida, luego renunciando al dominio ilimitado sobre la naturaleza. En caso contrario la técnica toma el lugar de la naturaleza y el hombre pierde la libertad recién vislumbrada.

A esto se suma que, como signo distintivo de la cultura y de la historia intelectual del Occidente, tanto en la filosofía y en la ciencia pero también en la religión, es difícil encontrar posiciones que reconozcan un valor en sí a la naturaleza. Esto tiene indudablemente como distintivo una relación agresiva, de conflicto y de lucha, y el mantenimiento de un tal comportamiento alimentado por el desarrollo científico y técnico que enraízan en un prejuicio heroico, para no decir formas de explotación destructivas.

\section{EL ANTROPOCENTRISMO Y EL MITO ORIGINAL La filosofía de la Naturaleza en las religiones judeo-cristianas}

Al plantearnos la pregunta, y con todo derecho, acerca de las razones por las que se ha desembocado en la actual crisis ecológica, tendría que contestarse que estas razones descansan en nuestra tradición y evolución cultural, esto es, la evolución de la rama cultural Occidental, y Judeo -Cristiana, entre otras. Asimismo, rastrear las fuentes del antropocentrismo lleva ineludiblemente, también, a la religión judeo- cristiana como engendradora de la mentalidad de dominio sobre la naturaleza en la cultura occidental, lo que a su vez nos informa de su visión filosófica.

A diferencia de las filosofías orientales respecto a la naturaleza, para las cuales el hombre es un elemento tan igual que el resto de criaturas y cosas, en las ideologías occidentales, entre ellas la religión judeo-cristiana, además de este reconocimiento se exalta la supremacía del hombre sobre el resto de lo existente.

Alberto Pecei en La calidad humana (1979), también cree descubrir las raíces de la crisis cultural de Occidente, incluyendo a la crisis ecológica, en la civilización emanada de la tradición judeo- cristiana, difundida, sucesivamente, en todas las direcciones; civilización en la que se destaca la idolatría al "hombre" y su superlativa superioridad en el mundo; además de justificar moralmente todas sus acciones para reafirmar esta superioridad y alcanzar sus objetivos. (p: 23)

También M. Horkheimer, citado por Pecei (Ibíd.), nos muestra esta línea de corresponsabilidad religiosa, cuando cree encontrar en el Génesis una actitud pragmática que termina, después, en la insensibilidad hacia la naturaleza. Afirmando, que en los primeros capítulos de la Biblia, se encuentra que todas las criaturas deben estar sometidas al hombre; y que únicamente han cambiado los métodos y las manifestaciones de este sometimiento. Asimismo, considera que las raras invitaciones a la conservación de las especies animales son "instrumentales", no implicando una obligación para el hombre, sino tan sólo una "tutela" de su sensibilidad moral.

Sigue afirmando Pecei que para la "ideología occidental de la conquista y de la expansión", a la cual la religión Cristiana ha brindado una clara contribución, "las otras 
criaturas del reino animal, vegetal o mineral no tendrían derecho a la residencia en la tierra, a menos que sirvan exclusivamente a los fines del hombre (...), nosotros concebimos la naturaleza como una realidad que tenemos en arriendo (...). No se admite un margen que permita la vida, el crecimiento y el desarrollo de cosas que no sean directamente útiles" (Pecei, 1979: 79,80). De lo que se desprende que estaríamos "condenados al desarrollo". Es decir, que como consecuencia de la desvalorización que se hace del mundo, que al ser representado como "creación divina", necesariamente, resulta ser "diferente"del creador; por consiguiente, así ausente de cualquier participación divina en sí, no hay, pues, justificación que amerite respeto hacia ella.

En esta misma idea de un mundo desvalorizado y sin derecho al respeto sigue sosteniendo Pecei, que:"El ente no contiene en cuanto tal significado alguno, es incompleto hasta que sobreviene el hombre que con su intervención le conferirá sentido. El ente yace privado de significado y espera que el hombre se lo confiera (...) mediante la razón, o sea, con la ciencia y con la técnica (...) El hombre es, por así decirlo, la prolongación del brazo de Dios, que da un significado a la materia, que de por sí es insignificante" (Ibíd.: 81)

En síntesis, para nuestro autor, tanto el cristianismo como el judaísmo son religiones "intolerantes" y la actitud de desprecio por el mundo es común a ambas. Sin embargo, estimamos que existe una relación entre religión y sentimiento hacia el mundo de la naturaleza que, sobre todo, en la actualidad se hace más patente este interés por esta problemática.

Ahora, cabría interrogarse si, efectivamente, la mentalidad de dominio encuentra sus raíces en la cultura judeo-cristiana, o de repente, más bien ésta no es sino un elemento en la construcción de esta mentalidad. Nuestro autor nos sugiere alguna respuesta, diciéndonos que en el pensamiento judío primitivo, está ausente la "mentalidad cientificista" y que la tierra es sentida y vivida como un don; pero que, tanto para el judaísmo como para el cristianismo la naturaleza "no es sagrada", por lo tanto no es ningún "sacrilegio" usarla.

\section{Críticas a la teología de la creación}

Para García Rubio en su artículo ¿Dominad la Tierra? (1995), la teología de la creación con su dimensión antropológica y, especialmente, con la importancia atribuida al mandato de dominar la Tierra, está siendo actualmente cuestionada; crítica que ha surgido en los países más ricos y desarrollados. Así por ejemplo, nos dice que G. Bateson, ya en 1970, planteaba la cuestión desnuda y crudamente:

"Si ustedes colocan a Dios fuera del universo, en aras de su creación, y si ustedes cuentan que han sido creados a "Su" imagen, entonces ustedes se considerarán, de un modo totalmente lógico, como exteriores a las cosas que les rodean, e incluso opuestos a ellas. Y como ustedes se apropian de todo lo que pertenece al espíritu para ustedes solos, pensarán que el mundo que les rodea se encuentra totalmente privado de este espíritu, y que, por tanto, no tiene derecho a ninguna consideración moral o ética. El medio ambiente parecerá que les pertenece para el único objetivo de ser explotado por ustedes.

Así, pensarán que la unidad de sobrevivencia estará compuesta por ustedes mismos, por sus semejantes y por sus próximos, situándolos en oposición al medio ambiente de 
otras unidades sociales y de otras razas, o de los animales o, incluso, de los vegetales". Si a este tipo de relación con la naturaleza unimos la posesión de una tecnología avanzada, las "oportunidades de supervivencia serán las mismas que las de una bola de nieve en el infierno" (p: 4). Estas afirmaciones de G. Bateson configuran una dura acusación contra la fe bíblica en el Dios creador o, al menos, contra la interpretación occidental de esa fe.

Según García Rubio (1995), que L. White, J. Cobb, C. Amery y otros, han hecho acusaciones semejantes. Nos dice que para estos autores, el mandato del Génesis de "dominar la tierra" (Génesis: 1,28) comportó consecuencias desastrosas en la época de la Revolución Industrial. La cosificación, manipulación, degradación y destrucción del medio ambiente encontraría en el relato Sacerdotal de la creación una raíz profunda.

L. White (comenta García Rubio: Ibid) critica por igual la ideología subyacente a la ciencia moderna y a la visión antropológica de la Iglesia, pues ambas presuponen algo en común: la consideración del hombre como alguien radicalmente superior y destacado en el seno de la naturaleza desacralizada por la ciencia y por la fe cristiana. La crítica contra la arrogancia de la civilización Industrial se aplica ahora también a las Iglesias y al hombre cristiano occidental. Continua afirmando que, según L. White, el orgullo y el distanciamiento cristiano respecto de la naturaleza "que encontrarían su fundamento en la teología de la creación" penetran hondo en la ideología moderna del progreso y en el modo como se ha desarrollado y aplicado a la técnica (p: 6).

En conclusión, de lo expuesto se puede inferir que el cristianismo es acusado de corresponsable de haber dado fundamento y de alimentar el proceso seguido por la civilización Industrial, con todas sus aberraciones. Esto significa que antiguas críticas que se hacían al cristianismo como de alienación, de huida del mundo, de oposición al progreso, y otras semejantes, han dado paso a nuevas acusaciones pero en sentido contrario, tales como: que el cristianismo tendría una gran parte de culpa en el descontrolado dinamismo del progreso moderno y en la hybris de la civilización industrial, que están degradando gravemente el medio ambiente y llevando al hombre muy cerca de la autodestrucción. 


\section{REFERENCIAS BIBLIOGRÁFICAS}

Abugattas, J. (Abril de 1992). Marco conceptual de la ciencia y la tecnología. Alma Mater, (1), 13-32, Lima, UNMSM

Becker, y Gómez, P. C. Da Costa (1993). Meio Amiente: matriz do pensamento geografico. En: Vieira, Paulo. As ciencias sociais e a questao ambiental. APED e UFPa, Rio de Janeiro.

García, A. (1995). ¿Dominad la Tierra? Aportaciones teológicas sobre el problema ecológico. http://www.pangea.org/ecologia_social.htm

Goncalves, C. (1990). Caminhos do meio ambiente. Sao Paulo: Edit. Contexto.

Gould. S.J. (1994). Otto piccoli parcellini. Riflesisoi di storia naturale. Milano: Bompiani.

La Torre, M. A. (1993). Ecología y Moral. Bilbao: Edit. DESCLEE DE BROWER.

Leis, W. (1972). Scienza e dominio. II "dominio sulla natura": storia di una ideologia. Milano: Longanesi.

Moreira, R. (1993). O circulo e a espiral. A crise paradigmática do mundo moderno. Rio de Janeiro: Obra Aberta/ Coautor.

O’Briant, W. (1974). "Man, nature and the History of Philosophy", in W.T. Blackkstone (ed) Philosophy and Environmental Crisis. University of Georgia Press. Athenas p.79.

Pecei, A. (1979). La Condición Humana. Madrid: Laia.

Rivera, J. (1994). "La concepción de la naturaleza en el pensamiento occidental y en el pensamiento andino- amazónico del Perú." En: Logos Latinoamericano. Revista del IIPPLA. Año 1. N.1.

Taguieff. P.A. (1994). La forza del pregiudizio. Bologna "Appendice" de la primera parte de la Etica de Baruch Espinoza. 